\title{
RESPONSABILIDADE SOCIAL DA EMPRESA, PANDEMIA E O DIREITO BRASILEIRO ENTRE LIBERDADE E SOLIDARIEDADE
}

\author{
Francisco Cardozo Oliveira ${ }^{1}$ \\ Luiz Eduardo Gunther ${ }^{2}$
}

\section{RESUMO}

O artigo faz análise dos fundamentos sociais e jurídicos das ações de responsabilidade social das empresas no contexto da pandemia do Covid-19 no Brasil, e no confronto entre tutela da liberdade e promoção da solidariedade. Desde uma perspectiva jusfilosófica, investiga-se o alcance da normatividade das ações de responsabilidade social mediante estratégias de regulação jurídica e de compromissos éticos e morais assumidos pelas empresas. A análise aponta para uma situação em que o desenvolvimento de ações de responsabilidade social pelas empresas no Brasil não observa o eixo de conexão entre tutela da liberdade social e promoção da solidariedade.

PALAVRAS-CHAVE: responsabilidade social; empresas; liberdade; solidariedade; direito

\section{SOCIAL RESPONSIBILITY OF THE COMPANY, PANDEMIA AND THE BRAZILIAN LAW BETWEEN FREEDOM AND SOLIDARITY}

\begin{abstract}
The article analyzes the social and legal foundations of corporate social responsibility actions, in the context of the Covid-19 pandemic in Brazil and in the confrontation between the protection of freedom and the promotion of solidarity. From a jusphilosophical perspective, is investigated the scope of the normativity of social responsibility actions through legal regulation strategies and ethical and moral commitments assumed by companies. The analysis points to a situation in which the development of social responsibility actions by companies in Brazil does not observe the connection axis between the protection of social freedom and the promotion of solidarity.
\end{abstract}

KEY WORDS: social responsability; companies; freedom; solidarity; law.

\section{INTRODUÇÃO}

\footnotetext{
${ }^{1}$ Doutor em Direito pela UFPR, professor do PPGD do UNICURITIBA e Juiz de Direito no Tribunal de Justiça do Paraná. E-mail xikocardozo@msn.com.

${ }^{2}$ Doutor em Direito pela UFPR, professor do PPGD do UNICURITIBA, Desembargador do Trabalho no TRT9. Email luiz.gunther@uol.com.br.
} 
O artigo faz análise interdisciplinar em torno do eixo de relação ou de confronto entre liberdade e solidariedade, na perspectiva de conferir fundamento jurídico às ações de responsabilidade social das empresas, em face da pandemia do Covid-19 no Brasil. Trata-se de identificar o suporte normativo das ações de responsabilidade social das empresas, relacionadas à pandemia do Covid-19, e seus efeitos em termos de efetividade de direitos na dinâmica de integração social no Brasil. A ênfase das ações de responsabilidade social das empresas pode estar voltada tanto para resguardar o exercício da liberdade e os interesses individuais, como para promover a solidariedade e a proteção de interesses sociais. Em torno dessa dinâmica, fixa-se o caráter verdadeiramente social da ação de responsabilidade das empresas e seu compromisso com a integração social. Em razão dos objetivos fixados, colocase o seguinte problema de análise: Qual o alcance jurídico e de integração social das ações de responsabilidade social das empresas no contexto da pandemia do Covid-19 no Brasil? Para enfrentar o problema proposto, a análise se inicia pela reconstrução da normatividade da responsabilidade social das empresas. Na sequência, a análise trata dos limites de paradigmas jurídico-políticos e tecnológicos colocados pela pandemia do Covid-19, especificamente relacionados à questão da liberdade e da solidariedade. No final, a análise converge para indicar o alcance jurídico e de integração social das ações de responsabilidade social das empresas, na realidade brasileira, no confronto entre garantia de liberdades e promoção da solidariedade. Adota-se uma metodologia dialética e crítica, com apoio em referências documentais e bibliográficas.

\section{RECONSTRUÇÃO DA NORMATIVIDADE DA RESPONSABILIDADE SOCIAL DA EMPRESA EM FACE DA REALIDADE BRASILEIRA}

A utilidade do paradigma reconstrutivo na presente análise pressupõe a decomposição da normatividade da responsabilidade social da empresa em dois níveis; o primeiro leva em conta elementos do ordenamento jurídico; o segundo contempla elementos jusfilosóficos de normatividade implicados na ação de responsabilidade social da empresa. Ambos os níveis estão implicados, de modo que não seria o caso de traçar entre eles uma separação objetiva, mas de identificar o elo de passagem de um nível a outro. 


\subsection{Responsabilidade social da empresa em face do ordenamento jurídico}

A responsabilidade social da empresa contempla ações que, a rigor, não configuram espécie de obrigação disciplinada pelo ordenamento jurídico.

No caso brasileiro, a responsabilidade social da empresa está referida na legislação como espécie de incentivo a comportamentos solidários no âmbito da atividade empresarial. Nesse sentido, o $§ 4 .^{\circ}$ do art. 154 da Lei n. ${ }^{o}$ 6404/1976, afirma que o conselho de administração ou a diretoria podem autorizar a prática de atos gratuitos razoáveis em benefício dos empregados ou da comunidade de que participe a empresa, tendo em vista suas responsabilidades sociais. Esse mesmo artigo também afirma que o administrador deve exercer suas atribuições de acordo com as exigências da função social da empresa. A própria lei, portanto, elabora a diferença entre função social e responsabilidade social da empresa. Enquanto a função social implica dever a cargo do administrador no exercício das atribuições de sua competência, a ação da responsabilidade social se restringe a uma faculdade a critério do conselho de administração de praticar atos gratuitos em favor dos empregados e da comunidade. A função social da empresa tem caráter obrigatório, diferentemente da responsabilidade social que, a princípio, parece não assumir os contornos de obrigação jurídica. A exemplo do que se observa mais recentemente na Lei n. $^{\circ}$ 13709/2018 e na Lei n. ${ }^{\circ}$ 13986/2020, a regulação jurídica da responsabilidade social da empresa no Brasil assume caráter promocional, na linha do proposto por Norberto Bobbio para a superação dos impasses do positivismo jurídico (2007). Observa-se, portanto, que a regulação jurídica da responsabilidade social da empresa na legislação brasileira, na medida em que assume os contornos de faculdade de ação, não destoa do sentido histórico que assumiu o instituto, de liberalidade individual, com feição filantrópica.

O caráter estritamente voluntarista das ações de responsabilidade social da empresa tem sido confrontado com as possibilidades de juridificação do instituto. Tratar-se-ia de uma espécie de conversão de valor ético em norma jurídica. Nessa direção, Peter O. Mulbert afirma que a responsabilidade social da empresa pode adquirir natureza jurídica, no bojo de uma nova estrutura normativa que, na esteira da transformação proposta por Norberto Bobbio, promova a passagem de um ordenamento jurídico repressivo para um ordenamento jurídico 
promocional. De acordo com essa perspectiva, as ações de responsabilidade social da empresa seriam premiadas e encorajadas. $\mathrm{O}$ direito promocional incentivaria ações de responsabilidade social por parte das empresas, no contexto de uma sociedade em que "pessoas e empresas estão conscientes dos seus direitos e das suas responsabilidades, desfrutam de vantagens que o direito lhes confere e cumprem as suas obrigações de forma a evitar conflitos" (2011, p. 599-632).

Há quem busque manter a responsabilidade social da empresa sob a orientação normativa de uma ética empresarial. Embora reconheça a necessidade de uma lei disciplinadora das ações de responsabilidade social da empresa, Sharon Cristine Ferreira de Souza afirma que a ética empresarial, que tenha como bases a confiança e a cooperação, se revela útil na regulação do instituto; ela defende, inclusive, o alinhamento da ética empresarial à ética do discurso, nos termos do formulado por Jürgen Habermas (2011, p. 633-656). Na mesma linha de fundamentos habermasianos, a partir da racionalidade comunicativa e de democracia deliberativa, Leandro José Ferreira e Magno Federici Gomes defendem a elaboração de um programa de compliance e de governança participativa, afinado com a responsabilidade social, na busca de solução de conflitos ambientais (2021, p. 177-204).

A defesa de Sharon Cristine Ferreira de Souza de uma ética empresarial, reguladora da responsabilidade social da empresa, reflete as premissas fixadas por Adela Cortina para a administração empresarial pós-taylorista de substituição do princípio da obediência pelo princípio da responsabilidade. Segundo Adela Cortina, a complexidade do ambiente social demanda a compreensão da coexistência de uma ética individual e de uma ética corporativa, de modo que as empresas assumam o compromisso de que suas ações tem consequências sociais; assim, competiria a empresa assumir reponsabilidades sociais, por exemplo, em relação ao meio ambiente (2008, p. 81).

Também é importante mencionar que no Brasil Ana Frazão e Angelo Gamba Prata de Carvalho seguem a premissa de uma normatividade ética para a responsabilidade social da empresa que eles qualificam de atos voluntários do empresário, que não se confundem com filantropia, na medida em que a ação modifica a estrutura empresarial (2017, p. 200-223).

Verifica-se que, de um lado, o direito relega a normatividade da responsabilidade social da empresa para uma espécie de regulação indireta, de modo a preservar a liberdade de ação por parte da empresa, na linha da tradição utilitarista, que está arraigada na cultura de 
operação dos mercados. De outro lado, a defesa de uma normatividade ética aposta no engajamento das empresas em ações de responsabilidade social. Em ambas as situações, emerge o caráter individualista da ação de responsabilidade social da empresa.

A regulação da responsabilidade social da empresa reproduz o dilema em torno da conexão entre ação individual e sociedade. Trata-se, em resumo, do modo como a ação individual conduz à integração social. Resulta necessário, portanto, seguir uma perspectiva que permita compreender o modo como a ação de responsabilidade social das empresas é capaz de assegurar coesão e, consequentemente, integração social.

Partindo da premissa de que a responsabilidade social das empresas possa contemplar um conteúdo ético, a mensuração da normatividade da ação de responsabilidade social precisa considerar a materialidade da vida em sociedade e seus reflexos sistêmicos no ordenamento jurídico. Logo, a compreensão normativa das ações de responsabilidade social das empresas implica considerar o modo como a integração social está imbricada com os fundamentos do ordenamento jurídico. Considerado o sentido da análise, essa imbricação pode ser tratada desde o paradigma de relações de reconhecimento, apoiada em Hegel, e de um paradigma linguístico e sistêmico, de relações comunicativas, com base em Habermas.

\subsection{Responsabilidade social das empresas e fundamentos jusfilosóficos}

Em Hegel a ideia de eticidade (Sittlichkeit) envolve o processo de emancipação da pessoa na vida em sociedade e, ao mesmo tempo, o modo como se desenvolve a relação da pessoa com os outros (1982). A ideia de eticidade permite a Hegel objetivar o percurso de transformação da pessoa, comprometida com suas necessidades pessoais, no confronto com as exigências de reconhecimento de direitos e de convivência com o outro. Axel Honneth buscou atualizar o pensamento de Hegel, em termos de uma teoria do reconhecimento compreendida, na questão econômica, como a tentativa de admitir que as atividades mediadas pelo mercado, nas economias capitalistas, apesar das "zonas" negativas, podem constituir um todo ético. Para isso, Hegel teria visto as ações individuais inseridas em uma coletividade voltada para realizar a liberdade geral e individual; assim, os comportamentos intersubjetivos forneceriam a base para o exercício de uma liberdade ampliada, cuja normatividade acabaria refletida no 
sistema jurídico. Busca-se, desse modo, elaborar a conexão entre ação individual e sistematização de direitos, pela mediação do mercado (2009, p. 41).

Especificamente sobre os efeitos da responsabilidade social das empresas, no contexto das práticas de mercado, Axel Honneth afirma que as decisões econômicas mais racionais levam em conta uma perspectiva de responsabilidade social; assim, diz ele, a legitimidade da economia de mercado repousa na possibilidade de realização da liberdade social; o intercâmbio mediado pelo mercado, sujeito a satisfação de normas e valores, não se destina a seguir interesses egocêntricos, mas deve permitir articular as orientações individuais em proveito de que a liberdade de um se converta na liberdade do outro (2013, p. 250-254). A responsabilidade social da empresa, portanto, não é algo externo a atividade mercantil; a ação da empresa no mercado adquire racionalidade na medida em que informada pelo sistema de normas e pela responsabilidade social. Conjuga-se no pensamento hegeliano a conexão da ação individual com a sociedade (sistema social).

Em outro percurso, mas na mesma direção, Jürgen Habermas elabora os fundamentos da virada linguística, que teria permitido o salto para a comunicação intersubjetiva, capaz de dar suporte a formas de consenso na vida social. Trata-se de elaborar a conexão entre ação individual e sistema social (sociedade) mediante uma racionalidade comunicativa. Depois de elaborar a crítica da racionalidade instrumental, característica do mercado, Habermas sustenta que a integração social pode operar em duas vias: a) a via do agir orientado ao entendimento que constrói o mundo da vida e b) a via da integração sistêmica em que a sociedade é representada de acordo com um modelo de sistema autorregulado. A evolução social na modernidade, portanto, opera mediante a diferenciação entre mundo da vida e sistema. Do ponto de vista sistêmico, a diferenciação atuaria para abolir a linguagem do mundo da vida em favor da autonomia organizacional. Nesse sentido, a atividade empresarial tende a configurar um subsistema que atua de forma autônoma, liberado dos contextos de mundo da vida estruturados mediante ação comunicativa; em resumo, a sistematização tende a isolar os conflitos inerentes à comunicação intersubjetiva, de modo que se configura uma disjunção entre sistemas e mundo da vida. $\mathrm{O}$ mundo da vida funcionaria como entorno do sistema econômico e, com isso, corre o risco de colonização (capturado pela racionalidade instrumental), de que podem resultar formas de patologias sociais (2012).

\footnotetext{
Revista Brasileira de Direito Empresarial | e-ISSN: 2526-0235 | Encontro Virtual | v. 7 | n. 2 | p. $39-57$ | Jul/Dez. 2021. 
$\mathrm{Na}$ concepção de integração social formulada por Habermas emerge o caráter conflitivo da evolução social na modernidade e da própria economia capitalista, que ele procura dar solução por meio de uma racionalidade comunicativa. Na formulação proposta, a ação de responsabilidade social das empresas também surge inserida na atividade empresarial propriamente dita e deve ser mensurada em termos de possibilidade de, para além da integração sistêmica, ser capaz de assegurar a racionalidade comunicativa que garante a integração social, e consequentemente, solidariedade, e que opera na via do mundo da vida.

A síntese da reconstrução normativa da responsabilidade social das empresas, em face da realidade brasileira, aponta para uma encruzilhada; enquanto no direito brasileiro a regulação da responsabilidade social das empresas está atrelada a fundamentos de preservação da ação individual e voluntarista da empresa ou do empresário, de inspiração filantrópica, a jusfilosofia aponta para a necessidade de assimilação de fundamentos de responsabilidade social da empresa capazes de fazer a conexão entre ação individual e sistema social (sociedade), de modo a conduzir a novos patamares de integração social, mediante ampliação de liberdade social e de solidariedade.

Seria o caso, portanto, de verificar quais contornos assumiram os fundamentos de liberdade e solidariedade, em face do contexto da pandemia do Covid-19, para, na sequência, revisitar a situação brasileira, à luz dos pressupostos jusfilosóficos de responsabilidade social das empresas.

\section{PANDEMIA, LIBERDADE, SOLIDARIDADE E SEUS REFLEXOS NOS FUNDAMENTOS DE RESPONSABILIDADE SOCIAL DA EMPRESA}

A pandemia do Covid-19 colocou em perspectiva uma das questões centrais na evolução da modernidade, que é a preservação da vida. A pandemia do Covid-19 desafia interesses políticos e tecnológicos, paradigmas científicos, jurídicos e conceitos filosóficos. Não é tanto o limite e o perigo da morte que está em questão, mas as necessidades de continuação da vida que determinam o modo de enfrentamento da pandemia. De resto, como já havia demonstrado Michel Foucault (2008), o biopoder se exerce sobre a vida e o corpo, de modo que é a vida, e não a morte que, na evolução da modernidade, suscita reflexão sobre os limites da existencialidade da pessoa. 
No Brasil, a salvaguarda da vida, durante a pandemia do Covid-19, intensificou disputas ideológicas e questionou hegemonias. Convém, portanto, balizar os reflexos da pandemia do Covid-19 no direito, em torno dos eixos de tutela jurídica da liberdade e da solidariedade, bem como a repercussão nas ações de responsabilidade social das empresas, para o que pode ser interessante partir do confronto filosófico sobre os tempos de pandemia entre Giorgio Agamben e Slavoj Zizek.

\subsection{A tutela da liberdade e da solidariedade em disputa no contexto do Covid-19}

Giorgio Agamben se insurge contra as medidas governamentais de prevenção do contágio e afirma que está em jogo a manutenção da liberdade do indivíduo. A necessidade de prevenção, segundo Agamben, instaura o medo que conduz as pessoas a aderir a ordens de fechamento de escolas, de paralisação de atividades, encontros e atividades culturais. Trata-se, diz ele, de uma espécie de aprofundamento do estado de exceção que se tornou normal. A sociedade que se permite viver em permanente estado de emergência deixou de ser uma sociedade livre; sacrificou-se a liberdade por razões de segurança e essa situação conduz ao perene estado de medo e de insegurança (2020, p. 9-16).

Para Agamben, a pandemia suscita reflexões no sentido de que a facilidade com que as pessoas aceitaram as restrições impostas pela administração pública na Itália permitiria afirmar que, antes mesmo da emergência, as condições de vida já estavam degradadas; as pessoas também teriam perdido a fé na convivência comum e se agarram a nua existência biológica, que é preciso manter e salvar (2020, p. 18-19).

As medidas de distanciamento social, segundo Agamben, criaram uma espécie de massa de pessoas invertida, que se mantém isoladas umas das outras, onde a densidade e a passividade impediriam qualquer movimento realmente livre. E ele enfatiza que caberia aos juristas examinar as restrições à liberdade a luz da Constituição, mas eles guardam silêncio sobre o que lhes concerne (2020, p. 20-26).

Como se observa, a ênfase da crítica formulada por Giorgio Agamben se situa na defesa da liberdade contra as medidas de isolamento social e de restrição de atividades durante a pandemia do Covid-19.

\footnotetext{
Revista Brasileira de Direito Empresarial | e-ISSN: 2526-0235 | Encontro Virtual | v. 7 | n. 2 | p. $39-57$ | Jul/Dez. 2021. 
Slavoj Zizek concorda em que as medidas de isolamento social, muros e quarentenas não são suficientes para enfrentar os desafios da pandemia do Covid-19, e que seria necessária uma espécie de solidariedade incondicional e respostas globalmente articuladas. Ele ressalta que a pandemia carrega um potencial emancipatório, na medida em que alivia a pressão do consumismo, da possibilidade de anonimato e da liberação das exigências sociais de reconhecimento. De acordo com Zizek, a aceitação da fragilidade da vida e da existência diante do coronavírus deve estimular a mobilização em torno da solidariedade coletiva (2021, p. 24-25).

Do ponto de vista socioeconômico, Salavoj Zizek sustenta que a pandemia do coronavírus indica os limites da economia capitalista e que se impõe a necessidade de mudanças, dado que não é mais possível viver a vida como antes. A catástrofe serve para refletir sobre as bases da vida social e colocar em perspectiva que os valores liberais estão em crise e somente uma mudança radical é capaz de salvá-los (2020, p. 28-31).

A crise social desencadeada pelo coronavírus, segundo Zizek, impõe admitir que não haverá retorno ao normal. Uma nova forma de vida terá que ser construída a partir do tempo de pandemia (2020, p. 34-36).

Contra Agamben, Zizek sustenta que se é fato que as restrições sanitárias implicam limites ao exercício de liberdades, o que deve ser ressaltado é que a ameaça viral cria novas formas de solidariedade, em que manter distanciamento social, usar máscaras e lavar as mãos, considerada a materialidade da vida, passa a constituir uma nova forma de preocupação com o outro. Ele cita o exemplo do Decamerão, de Boccaccio, para ressaltar que somente os privilegiados podem se dar ao luxo da proximidade e do abraço, a exemplo dos jovens que se abrigaram em isolamento e festas, quando a peste atingiu Florença (2020, p. 53-59).

Finalmente, Slavoj Zizek aponta para formas de transfucionalização, em que modelos de agenciamento se transformaram durante a pandemia, a exemplo das facções do tráfico de drogas, nas favelas do Rio de Janeiro, que decretaram trégua na disputa por territórios para permitir ajuda aos mais fracos e idosos da comunidade (2020, p. 79-92).

Em torno da premissa de transfucionalização, Slavoj Zizek enxerga novas formas de solidariedade surgidas do contexto de convivência com o coronavírus, de que podem resultar mudanças sociais em direção a novas formas de vida. 


\subsection{A relação entre liberdade e solidariedade e o caráter social da responsabilidade social das empresas}

O confronto filosófico entre Giogio Agamben e Slavoj Zizek, em torno da realidade da pandemia do coronavírus, indica a necessidade de reflexão sobre a conexão entre liberdade e solidariedade e seus reflexos no ordenamento jurídico.

Ao invés de pensar os limites e a separação entre liberdade e solidariedade, a pandemia do coronavírus parece indicar a necessidade de pensar formas de interrelação entre defesa da liberdade e promoção da solidariedade.

A conexão entre liberdade e solidariedade está arraigada na evolução da modernidade. Nesse sentido, a Revolução Francesa contemplava o entrelaçamento entre liberdade, igualdade e fraternidade. Ao longo da história, o ideário liberal deu primazia à liberdade em detrimento da promoção da igualdade e da fraternidade. Trata-se, portanto, de operar o resgate da imbricação social e jurídica entre liberdade e solidariedade.

A tradição liberal traçou um limite abstrato para a liberdade traduzido na separação entre liberdades positivas e liberdades negativas que, no plano jurídico, assumiu a dicotomia entre liberdade formal e liberdade material ou real. Nesse sentido, Friedrich Hayek define liberdade pelo aspecto negativo de ausência de coerção, embora reconheça que a liberdade somente encontra seu verdadeiro sentido na relação do indivíduo com o outro, dado que a coerção somente pode exercida por uma pessoa em relação a outra, o que significa admitir o caráter social da liberdade; segundo Hayek, os limites da coerção acabam estabelecidos pelo Estado através da lei (1983, p 27-38). Domenico Losurdo chama a atenção para a reflexão que Hegel faz em torno da herança da Revolução Francesa, no sentido de pensar o problema da liberdade a partir do conflito de liberdades que se manifesta na evolução histórica da sociedade moderna. Hegel tornou mais complexo o discurso da liberdade, na medida em que realça os contrastes que ele pode assumir quando se torna necessário distinguir a liberdade e a tirania, no contexto da evolução histórica da modernidade (2019, p. 439-440). Com efeito, se é certo que as liberdades negativas protegem a inviolabilidade da vida privada, as liberdades positivas, por outro lado, promovem a abertura para a consolidação do direito a titularização de direitos individuais e sociais, capazes de assegurar emancipação e autonomia. É nesse sentido que Hegel, na Filosofia do direito, afirma que a subsistência de cada um depende do 
livre-arbítrio e do sistema objetivo de carências; ou seja, assegurar a subsistência depende da pessoa e do modo como articuladas as necessidades na vida em sociedade. Assim, diz Hegel, o castigo à violação ao direito de propriedade implica a supressão das contingências que ameaçam a segurança das pessoas; em síntese, a preservação da liberdade depende de o bemestar das pessoas ser reconhecido como direito (2003, p. 202).

Nesta altura emerge a objetividade do ponto de contato na sociedade moderna entre liberdade e solidariedade; não é possível assegurar a liberdade sem que, ao mesmo tempo, esteja assegurado o direito de todos a vida digna.

O alcance da liberdade, tomada a materialidade da vida em sociedade, depende do grau de satisfação das carências, de modo que alcançar a liberdade passa pelo arranjo solidário de meios materiais capazes de assegurar a subsistência de todos. É nesse sentido que Axel Honneth elabora as premissas da ideia de liberdade social contraposta às patologias da ideia de liberdade jurídica.

O exercício da liberdade jurídica, segundo Honneth, com objetivos estratégicos, característicos da economia de mercado, inviabiliza a formação de relações sociais intersubjetivas, na medida em que não permite ação cooperativa e leva ao que ele denomina de patologias da liberdade jurídica. A regulação jurídica da liberdade aponta para os limites de paradigmas de uma concepção de ordenamento jurídico de cunho normativista, apoiado na abstração dos conceitos. O direito tutela uma forma de liberdade individual cujas condições de realização a sociedade não está em condições de garantir o que conduz a que, de um lado, a liberdade individual se restrinja a titularidade de direitos, dependente portanto da própria ordem jurídica, e, de outro, ocorra uma suspensão do exercício de direitos subjetivos, que depende do reconhecimento de obrigações intersubjetivas, de modo que a ideia de liberdade faz surgir uma espécie de personalidade jurídica formal; neste último caso, a repercussão na vida dos jovens exige que eles, de forma preventiva, evitem construir obrigações mútuas porque podem ser abandonados no futuro (2013, p. 99-129).

Em relação a liberdade social, Axel Honneth afirma que o social é condição para o exercício da liberdade mediante interação intersubjetiva no discurso. Ser livre, nesse sentido, significa encontrar com o outro mediante reconhecimento mútuo, no contexto de práticas intersubjetivas. Com apoio em Hegel, Axel Honneth afirma que é necessário um conjunto de instituições sociais para assegurar o exercício da liberdade, de modo que o sujeito deve 
integrar-se ao social para exercitar a liberdade. Assim, a liberdade individual depende da recepção de ações pelo grupo social. A liberdade social, por sua vez, depende da oportunidade de a pessoa participar de instituições de reconhecimento (2013, p. 64-90).

No plano social, a solidariedade encontra um ponto de conexão com a liberdade social, na medida em que o exercício da liberdade depende de um contexto de instituições capazes de propiciar oportunidades de reconhecimento na presença do outro. O que assegura a liberdade é a mediação da presença do outro. Consequentemente, não seria o caso de contrapor liberdade e solidariedade.

Em termos de fundamentos normativos de responsabilidade social das empresas é exatamente a ação solidária, necessária ao exercício da liberdade, que confere sentido a ação desencadeada pelas empresas no mercado. Assim, o caráter verdadeiramente social da ação de responsabilidade social das empresas residiria no potencial de solidariedade que possa assegurar emancipação e ampliação da liberdade social.

\section{O ALCANCE JURÍDICO E SOCIAL DAS AÇÕES DE RESPONSABILIDADE SOCIAL DAS EMPRESAS NA REALIDADE BRASILEIRA DA PANDEMIA DO COVID-19}

Estabelecidos os contornos de regulação jurídica da responsabilidade social das empresas, e definido o modo como a questão da liberdade está atrelada a da solidariedade, na evolução social da modernidade, impõe-se analisar o alcance jurídico e social das ações de responsabilidade social das empresas, em face das medidas de emergência do Covid-19 no Brasil. Nesse sentido, convém iniciar fazendo um inventário da efetividade do sistema jurídico brasileiro no enfrentamento das exigências de medidas protetivas em face da emergência do Covi-19 para, na sequência, identificar o que é fundamental na análise, que é o modo como as ações de responsabilidade social das empresas responderam aos desafios representados pelas necessidades de salvaguarda da liberdade e de promoção da solidariedade, e o que dessas ações possa ter resultado em termos de novo patamar de normatividade, com efeitos de integração social.

\subsection{Judicialização da pandemia do Covid-19 no Brasil e a questão da liberdade}


A Lei n. ${ }^{\circ}$ 13979/2020 definiu os critérios de enfrentamento da emergência sanitária decorrente da pandemia do Covid-19 no Brasil. Definiu-se na lei como objetivo básico a proteção da coletividade ficando autorizadas medidas de isolamento, quarentena e de restrição temporária de entrada e saída do país, além de providências específicas de caráter médicosanitário.

A regulação jurídica das medidas de emergência da pandemia do Covid-19 suscitou intensa judicialização no Brasil e, nesse sentido, esteve em sintonia com o que já ocorria em termos de tutela do direito à saúde. O diferencial da judicialização das questões relacionadas a pandemia do Covid-19 ficou por conta dos reflexos políticos e ideológicos, a exemplo do que ocorria a nível mundial, embora no caso brasileiro tenha assumido conotações específicas em face da polarização que se consolidou ao longo de quase uma década no país.

Uma das medidas judiciais de grande repercussão social e política resultou da decisão do STF na Ação Direta de Inconstitucionalidade n. ${ }^{\circ}$ 6341-MC-REF/DF, de Relatoria redatora do Ministro Edson Fachin, que fixou a competência concorrente da União, Estados e Municípios para aplicar e fiscalizar as medidas necessárias à contenção da pandemia do Covi19. Nessa decisão, o STF afirmou que a competência da União para legislar acerca das medidas sanitárias necessárias ao combate da pandemia do Covid-19 não elimina a competência dos Estados e dos Municípios de realizar os serviços de saúde observado o contido nos artigos 196 e 198 da Constituição da República. Fixou-se o pressuposto de que as normas constitucionais não servem apenas para proteger a liberdade individual; servem também para o exercício da racionalidade coletiva, entendida como a capacidade do Estado de coordenar ações de forma eficiente. O julgado, portanto, sustenta a coexistência no texto da Constituição de tutela da liberdade individual e de promoção de ações de alcance coletivo que estejam direcionadas, obviamente, para a preservação dos interesses da pessoa.

Outra medida judicial de impacto social e político, e com efeitos diretos em termos de tutela da liberdade e promoção da solidariedade, resultou da decisão do STF na Ação Direta de Inconstitucionalidade n. ${ }^{\circ} 6586$ - DF, de Relatoria do Ministro Ricardo Lewandowski. Na decisão, o STF fez interpretação de conformidade constitucional dos incisos I, II e III do $§ 2 .^{\circ}$ do art. 3. ${ }^{\circ}$ da Lei n. ${ }^{\circ}$ 13979/2020 e fixou que a vacinação obrigatória, necessária para assegurar a imunidade da população, não equivale a submissão a vacinação 
forçada, incompatível com a garantia das liberdades fundamentais. De modo a compatibilizar o direito a não submissão a vacinação compulsória, o STF definiu que o caráter obrigatório da vacina pode ser implementado mediante sanções indiretas, como a proibição dos não vacinados de frequência a determinados lugares, nos termos da lei. A decisão se apoia no direito fundamental a intangibilidade do corpo, de preservação da integridade física e psíquica da pessoa, salvaguarda albergada pelo princípio da dignidade da pessoa humana. Do ponto de vista sanitário, a decisão baseou-se no direito ao exercício do consentimento livre e informado. Assim, o caráter obrigatório da vacinação, juridicamente respaldado na tradição do ordenamento jurídico brasileiro, não se revelaria incompatível com a vedação da vacinação forçada. Particularmente interessante é a lembrança do Ministro Gilmar Mendes no julgamento da ADI n. ${ }^{\circ}$ 6586- DF do modo como o Tribunal Constitucional Alemão definiu o conflito entre direitos fundamentais, em face da necessidade de vacinação; a solução, segundo o Ministro, residiu em referendar a necessidade de vacinação das pessoas em razão do dever fundamental, no qual se insere o Estado, de preservação da vida.

Na solução normativa da Ação Direta de Inconstitucionalidade n. ${ }^{\circ}$ 6586-DF, o STF buscou salvaguardar os direitos de liberdade da pessoa e, ao mesmo tempo, promover ações de saúde solidárias. No sentido de promoção da solidariedade, a decisão assegurou a viabilidade jurídica da vacinação obrigatória e de programas de imunidade coletiva desenvolvidos pela União, Estados e Municípios, condensados no Programa Nacional de Imunização (PNI) contra o Covid-19. Em relação aos direitos de liberdade, a decisão do STF assegurou o direito da pessoa de não se submeter a ações de vacinação forçada, e mesmo de recusar-se a ser vacinada, neste último caso com os riscos de sanções indiretas. A solução jurídica alcançada no julgado parece não ter se refletido na realidade social no aumento de recusa a vacina; a maioria das pessoas, ainda que tenha dúvidas acerca da efetividade das vacinas disponibilizadas, tem aderido aos programas de vacinação disponibilizados pela União, Estados e Municípios.

A decisão do STF pode ter alcançado o objetivo de garantir a efetividade da norma jurídica, na medida em que a adesão a vacinação esteja sendo compreendida como garantia da vida de todas as pessoas em sociedade, nesse sentido em linha com os pressupostos de integração social. De qualquer modo, a adesão aos programas de vacinação, mesmo pelos recalcitrantes acerca da eficácia de vacinas, não reduziu o questionamento em termos de 
exercício da liberdade, em face do contexto de emergência da pandemia. As várias medidas de isolamento e de quarentena implementadas ao longo do período de pandemia atraíram inúmeros questionamentos em razão das restrições à liberdade e seus efeitos econômicos e sociais. Muitas empresas e empresários questionaram nos tribunais as restrições à liberdade de empresa, de iniciativa e de trabalho provocadas por medidas de isolamento e de quarentena. O desdobramento político desses questionamentos conduziu a uma contraposição das prioridades de políticas públicas, no sentido de preservar a atividade econômica, sob o discurso de evitar o aumento da pobreza, ou de dar primazia às medidas sanitárias de preservação da saúde e da vida das pessoas. Em torno dessa contraposição, esteve em causa a preservação da liberdade de um lado e, de outro, a promoção da solidariedade.

A judicialização das medidas de prevenção do Covid-19 no Brasil parece não ter indicado um caminho claro de respaldo ao caráter solidário do cuidado do outro, dado que permaneceu latente na sociedade a preocupação com a preservação da liberdade individual e da atividade econômica.

\subsection{Ação de responsabilidade social das empresas no Brasil entre liberdade e solidariedade}

A contraposição entre liberdade e solidariedade também emergiu na realidade brasileira naquilo que poderia ser qualificado de ações de responsabilidade social relacionadas ao enfrentamento da pandemia do Covid-19. Neste aspecto, algumas empresas se articularam para a compra privada de vacinas, a revelia do Sistema Único de Saúde - SUS, com o propósito de permitir que seus colabores pudessem alcançar o mais rapidamente possível níveis de imunidade contra o coronavírus e retornar ao trabalho.

A Lei n. ${ }^{\circ}$ 14125/2021 disciplinou a compra de vacinas por empresas e condicionou a iniciativa ao repasse para o Sistema Único de Saúde - SUS, de modo a prevenir a ocorrência de privilégios e distorções na prevenção do Covid-19. As empresas questionaram perante o Poder Judiciário a obrigatoriedade de entrega das vacinas para o Sistema Único de Saúde SUS. 
Outros empresários desenvolveram iniciativas para a aquisição de seringas e insumos disponibilizados para Estados e Municípios, a exemplo do movimento "Unidos pela Vacina"3, de forma a manter em andamento os programas públicos de vacinação.

Ainda que se possa ver em cada uma dessas iniciativas possibilidades de conjugação de esforços em prol da preservação da liberdade e da promoção da solidariedade, de forma conjunta, verifica-se que em cada uma delas sobressai de um lado a garantia da liberdade ou, de outro, a promoção da solidariedade. Na compra por empresas privadas de vacinas parece emergir o propósito de preservação de interesses individuais, com o que estaria em causa a garantia de liberdade. Na compra de seringas e insumos parece estar em causa o interesse social na manutenção dos programas de vacinação, com uma vinculação mais estreita com os propósitos de promoção da solidariedade.

Vistas as ações em seu conjunto, a compra de seringas e insumos contempla maior potencial de ampliação da liberdade social.

Em termos de resultados, o saldo de mais de 500.000 mortos em razão do Covid-194 e o aumento da pobreza no Brasil ${ }^{5}$ indicam que as iniciativas sociais, as ações governamentais e a tutela jurídica não se revelaram suficientes para o combate ao coronavírus e para a preservação da economia.

Resta verificar o modo como essa constatação de fatos na realidade social repercute efeitos no patamar de evolução da normatividade, com potencial de integração social, inclusive em relação aos fundamentos sociojurídicos de ações de responsabilidade social das empresas.

Para enfrentar esta última questão a que conduz a análise é necessário retomar as premissas fixadas por Hegel e Habermas.

Como visto anteriormente, em Hegel, atualizado por Axel Honneth, as ações de responsabilidade social da empresa devem fornecer um patamar de racionalidade às atividades empresariais, capaz de assegurar a ampliação da liberdade social na economia de mercado. Já para Habermas, a responsabilidade social inserida na atividade empresarial deve propiciar

\footnotetext{
${ }^{3}$ https://www.unidospelavacina.org.br/

${ }^{4}$ https://revistapesquisa.fapesp.br/um-guia-do-novo-coronavirus/; consultado em 18.09.2021.

${ }^{5}$ https://www.cepal.org/pt-br/comunicados/pandemia-provoca-aumento-niveis-pobreza-sem-precedentesultimas-decadas-tem-forte consulta em 18.9.2021.
} 
integração sistêmica; também deve assegurar a racionalidade comunicativa que garante integração social e que opera na via do mundo da vida. Em ambas as perspectivas, é exatamente a ação solidária, inerente à responsabilidade social das empresas, que assegura emancipação e liberdade social.

Na situação brasileira, as ações de responsabilidade social, tomados os exemplos de compra de vacinas ou de seringas e insumos por empresas, indicam a falta de conexão entre a garantia da liberdade social e a promoção da solidariedade. É inegável, todavia, que em ambas as iniciativas se manifesta o propósito de solidariedade, em uma mais do que em outra. Mas elas não foram determinantes para alterar os rumos da política pública de vacinação. Assim, tomada a situação emergencial do Covid-19 como premissa, o indicativo é o de que, na sociedade brasileira, as ações de responsabilidade social das empresas não contemplam potencial de integração social suficiente para operar na realidade a promessa de ampliação de formas de liberdade social, mediante ações solidárias. Com isso, resulta limitada a dinâmica de integração social, comprometida com novo patamar de normatividade, o que não significa que a cultura socioeconômica brasileira não esteja comprometida com ações de responsabilidade social por parte das empresas dado que, conforme apurado por Sirlene Koprowski e Outros (2021, p. 488-502), a maior aceitação de ações de responsabilidade social das empresas ocorre, justamente, em sociedades de perfil individualista e desigual.

\section{CONCLUSÃO}

A análise pretendeu indicar o alcance jurídico e de integração social das ações de responsabilidade social das empresas no contexto da pandemia do Covid-19 no Brasil.

No percurso de enfrentamento do problema proposto, a análise indicou pelo menos três impasses: a) na ação responsabilidade social das empresas o ordenamento jurídico brasileiro preserva a liberdade individual do agente, enquanto os paradigmas jusfilosóficos apontam para uma teleologia da ação de responsabilidade social, comprometida com a ampliação de liberdade social, no rumo da solidariedade; b) os fundamentos de responsabilidade social das empresas repousam em uma ação solidária que confere sentido a ação desencadeada pelas empresas no mercado, do que deriva o potencial de emancipação e ampliação da liberdade social, e nisso reside o verdadeiro caráter social das ações de 
responsabilidade social das empresas; c) no Brasil as ações de responsabilidade social das empresas emergem desconectadas do propósito solidário de assegurar ampliação da liberdade social.

A título de síntese conclusiva, a análise parece indicar que a prática de ações de reponsabilidade social das empresas no Brasil está em linha de simetria com o modo como regulada a questão pelo ordenamento jurídico, no sentido de preservação da liberdade individual do empresário e das empresas.

Assim, a ação de responsabilidade social permanece sujeita a um compromisso ético e individual da empresa e do empresário com a sociedade. Em face dessa sujeição, a ação de responsabilidade social oscila entre manter-se atrelada ao espírito de filantropia ou servir a propósitos de marketing e de governança de territórios em benefício do aumento da lucratividade.

Ainda não está consolidada na realidade brasileira uma prática de ações de responsabilidade social das empresas comprometida com a conexão entre solidariedade e ampliação da liberdade social. De certa forma, a análise evidencia o modo como o Brasil está preso aos paradigmas da modernidade, de radicalização do propósito de uma sociedade jurídica, restrito a garantia formal da liberdade individual, sem que essa garantia seja capaz de permitir ampliação da liberdade social. Desse paradoxo resulta todo o potencial de conflito e de polarização, que dificulta a construção de consensos e de integração social. A permanência do impasse e o estreitamento de horizontes colocam o Brasil na vanguarda do pósmodernismo.

\section{REFERÊNCIAS BIBLIOGRÁFICAS}

AGAMBEN, Giorgio. Reflexões sobre a peste - ensaios em tempo de pandemia. São Paulo: Boitempo Editorial, 2020.

BOBBIO, Norberto. Da estrutura a função - novos estudos de teoria do direito. São Paulo: Editora Manole, 2007.

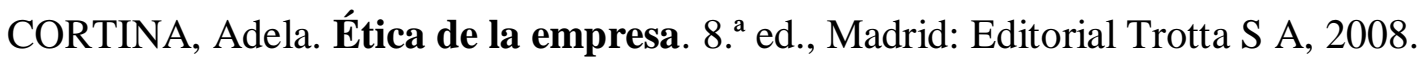

FERREIRA, Leandro José; GOMES, Magno Federici. Compliance, governança participativa e conflitos ambientais. In (Org.) SAMPAIO, José Adércio Leite; FABEL, Luciana Machado 
Teixeira. Responsabilidade social corporativa e direitos dos desastres. Rio de Janeiro: Editora Lumen Juris, 2021, vol. 1, pág. 177-204.

FOUCAULT, Michel. Nascimento da biopolítica. São Paulo: Martins Fontes, 2008.

FRAZÃO, Ana; CARVALHO, Angelo Gamba Prata de. Responsabilidade social empresarial. In (Org.) FRAZÃO, Ana. Constituição, empresa e mercado. Brasilia: UNB Faculdade de Direito - Gecem, 2017, p. 200-223.

HABERMAS, Jürgen. Teoria do agir comunicativo. São Paulo: Editora Martins Fontes, vol. 1 e $2,2012$.

HAYEK, Friedrich. Fundamentos da liberdade. Editora Visão, 1983.

HEGEL, G.W.F. El sistema de la eticidad. Madrid: Editora Nacional, 1982.

HEGEL, G.W.F. Princípios da filosofia do direito. São Paulo: Martins Fontes, 2003.

HONNETH, Axel. Luta por reconhecimento de direitos - a gramática moral dos conflitos sociais. 2. ${ }^{\text {e }}$ ed. São Paulo: Editora 34, 2009.

HONNETH, Axel. EI derecho de la libertad - esbozo de una eticidad democrática. Buenos Aires: Katz Editores, 2013.

KOPROWSKI, S., MAZZIONI, S., DAL MAGRO, C. B., ROSA, F. S., (2021). Cultura Nacional e Responsabilidade Social Corporativa. Revista Brasileira de Gestão de Negócios, 23(3), p.488-502.

LOSURDO, Domenico. Hegel e a liberdade dos modernos. São Paulo: Boitempo Editorial, 2019.

MULBERT, Peter O. Responsabilidade social das empresas através do direito e o direito à luz da responsabilidade social das empresas. In (Org.) COSTA, Alice Nunes, SANTOS, Maria João; SEABRA, Fernando Miguel; JORGE, Fátima. Responsabilidade social - uma visão ibero-americana. Coimbra: Edições Almedina S.A., 2011, p. 599-632.

SOUZA, Cristine Ferreira de Souza. O papel do direito no controle das políticas públicas de incentivo às empresas socialmente responsáveis: por uma lei de responsabilidade social. In (Org.) COSTA, Alice Nunes, SANTOS, Maria João; SEABRA, Fernando Miguel; JORGE, Fátima. Responsabilidade social - uma visão ibero-americana. Coimbra: Edições Almedina S.A., 2011, p. 633-656.

ZIZEK, Slavoj. Pandemia - covid-19 e a reinvenção do comunismo. São Paulo: Boitempo Editorial, 2020. 